\title{
Process optimization for development of low-calorie milk cake
}

\author{
Arvind, Ranjeet Pratap Singh and Shikha Pandhi
}

Received: 03 December 2018 / Accepted: 08 February 2019 / Published online: 18 April 2019

(c) Indian Dairy Association (India) 2019

\begin{abstract}
Among the indigenous dairy products, khoa and khoa based milk sweets have served as a good means of conserving and safeguarding surplus milk solids. Milk cake is the most popular heat desiccated milk based sweet which is characterized by its well-defined grainy texture and pronounced caramel flavor. In the present study, an attempt was made to develop a low-calorie milk cake with the incorporation of artificial sweetener and fat replacer in the milk using Response Surface Methodology and also, to study various physiochemical parameters of the optimized product. An RSM experiment was conducted with three variables viz., Milk Fat (1.0-3.0\%), Aspartame (0.3-0.5\%) and Gum Acacia (0.3-1.0\%). The average value of proximate chemical analysis of fat, protein, added sugar, moisture and ash was $5.30 \%, 17.31 \%, 0.00 \%, 17.23 \%$, and $2.37 \%$ respectively. Results showed that the level of fat and carbohydrate was decreased drastically, and helped in reducing the calorific value of milk cake. The energy value of low-calorie milk cake was reduced about half of the market milk cake as the energy value of low-calorie milk cake was $3.782 \mathrm{kcal} / \mathrm{gm}$ and market milk cake was $6.335 \mathrm{kcal} / \mathrm{gm}$.
\end{abstract}

Keywords: Fat replacer, Low-calorie, Milk cake, Optimization

\author{
Arvind $(\bowtie)$ \\ Centre of Food Science and Technology \\ Institute of Agricultural Sciences \\ Banaras Hindu University \\ Varanasi -221005, Uttar Pradesh, India \\ E-mail: arvind00000@gmail.com; Phone:+91-9793583702 \\ Ranjeet Pratap Singh and Shikha Pandhi \\ Centre of Food Science and Technology \\ Institute of Agricultural Sciences \\ Banaras Hindu University, Varanasi -221005, Uttar Pradesh, India
}

\section{Introduction}

India ranks first in the world milk production of 165.4 million tons of milk per annum with the per capita availability of $355 \mathrm{gm} / \mathrm{day}$ (NDDB, 2017). Use of diverse methods to prepare as well as preserve milk products have been reported in the very early literature. In the present context, Kalakand, Khurchan, Rabri, Burfi, Milk cake, etc. represents a range of commercially important heat desiccated milk products. Among the indigenous dairy products, khoa and khoa based milk sweets provide a good means of conserving and preserving surplus milk solids. It is estimated that about 7 percent of total milk in India is converted into heat and acid coagulated indigenous milk products among which kalakand and milk cake are one of the products (Bhutkar et al., 2015). Milk cake is the most popular desiccated milk based sweet characterized by well-defined grains with pronounced caramel flavor than Kalakand which is prepared from danedar (granular) variety of Khoa (Mathur, 1991). Modification of lifestyle habits may play an important role in changing food trends. The current trend amongst the consumers and in the food industry is towards the food products that contain lowcalorie sugar and fat-replacers due to increasing nutritional and health awareness for calorie reduction in the diet (Dilek et al., 2007). Aspartame, an artificial sweetener is used as a sugar substitute which is about 200 times sweeter than sucrose or table sugar. Aspartame is a methyl ester of the aspartic acid/ phenylalanine di-peptide due to this property, even though aspartame produce four kilocalorie of energy per gram when metabolized, the quantity of aspartame needed to produce a sweet taste is so small that its calorific contribution is negligible (Magnuson et al., 2007). As a food, acacia gum is used as an emulsifier, fat replacer and a thickening agent in icing, fillings, soft candy, chewing gum, and other confectionery. In the present study, an attempt was made to optimize the process for the manufacture of low-calorie milk cake using Response Surface Methodology. And also to study the various physiochemical properties of low-calorie milk cake.

\section{Materials and methods}

Milk of different fat percentage was collected from Amul outlet from the local market of Varanasi, Uttar Pradesh, Aspartame 
(artificial sweetener) made by NutraSweet Co., USA were procured from Kawarlal And Company, Chennai, India. Gum Acacia (fat replacer) was procured from Avantor performance India Ltd., Faridabad, Haryana, India and Citric acid from Sisco Research Laboratories Pvt. Ltd. Andheri (E), Mumbai, India.

\section{Preparation of low-calorie milk cake}

Low-calorie Milk Cake was prepared as per the procedure standardized by karwasra et al. (2001) with slight modification. For the preparation of low-calorie milk cake, toned milk (3 percent fat and 8.5 percent SNF) was taken and strained through a muslin cloth to remove dust and dirt particle. After straining, five liters of milk was taken in a shallow iron karahi and boiled till the volume of milk becomes half and then citric acid was added at the rate of 0.02 percent (weight/ volume of milk) and desiccation is continued. When the volume was reduced to one-third of the original volume of the milk, Gum acacia was added at the level of 0.49 percent (w/v). Further, desiccation was continued with fast stirring to obtain dough-like thick consistency followed by addition of aspartame at the rate of 0.23 percent $(\mathrm{w} / \mathrm{v})$, the hot dough was then transferred to a greased tray, and was slowly cooled in an insulated box for five to six hours. The bottom of the tray was cooled in ice water while the top of the tray was cooled slowly at room temperature. This result in deferential caramelization of the top and bottom of milk cake, the top layer gets a darker color and stronger flavor whereas rapidly cooled bottom layer retains white color. The flow chart of the preparation of low-calorie milk cake is shown in Figure 1.

\section{Experimental design and data analysis}

RSM was employed to optimize the percentage level of three independent variables such as milk fat, artificial sweetener, and Fat Replacer. The three independent variables used in the experimental design are presented in Table 1. The levels of each variable were established according to preliminary trials. Dependent variables considered were sensory analysis and textural properties such as color \& appearance, flavor, body \& texture, hardness, gumminess, chewiness. Also, the effect on the color was also considered. Response surface methodology was applied for experimental data using a commercial statistical package, Minitab 18 for the generation of response surface plots. The same software was used for statistical analysis of experimental data. The results were analyzed by a multiple linear regression method which describes the effects of variables in the first order, a three-factor interaction (3FI) and second order polynomial models. Experimental data were fitted to the selected models and regression coefficients were obtained. Statistical significance of the terms in the regression equation was examined by analysis of variance (ANOVA) for each response. A Pearsons correlation matrix on product responses and system parameters was carried out in order to determine correlation coefficients between parameters.
The experiments were done and responses were fitted in the design. After that each individual experiment, responses were analyzed to assess the effect of independent variables on them. Numerical optimization technique of the Design Expert software was used for simultaneous optimization of the multiple responses. The desired goals for each factor and response were chosen. The goals may be applicable to either factors or responses. The possible goals or constraints were: maximize, minimize, target, within range, none (for response only) and set to an exact value (for factors only). In order to search a solution maximizing multiple responses, the goals were combined into an overall composite function, called the desirability function. Desirability is an objective function that ranges from zero outside of the limits to one at the goal. The program of the software (design expert) seeks to maximize the function. The goal seeking begins at a random starting point and proceeds up the steepest slope to a maximum. By starting from several points in the design space, chances improve for finding the "best" local maximum.

The second order polynomial equation of the following form was fitted to the responses:

$\mathrm{Y}=\beta_{o}+\sum_{i=1}^{4} \beta_{i} X_{i}+\sum_{i=1}^{4} \beta_{i i} X_{i}^{2}+\sum_{i=1}^{3} \sum_{j=i H}^{4} \beta_{i j} X_{i} X_{j}$

Where,

$\mathrm{Y}=$ response variable

$\beta o, \beta_{\mathrm{i}}, \beta_{\mathrm{ii}} \& \beta_{\mathrm{ij}}=$ regression coefficient

$\mathrm{X}_{\mathrm{i}}, \mathrm{X}_{\mathrm{j}} \& \mathrm{X}_{\mathrm{ij}}=$ coded independent variables

Responses to optimize the level of fat replacer, artificial sweetener, and milk fat percentage

\section{Sensory evaluation}

Low-calorie Milk Cake was analyzed for different sensory characteristics like color and appearance, body and texture, flavor and overall acceptance by a panel of 9 semi-trained judges from the Center of Food Science and Technology, Banaras Hindu University, Varanasi and analysis was conducted in triplicate. Sensory evaluation was done at $25^{\circ} \mathrm{C}$ by using nine-point hedonic rating (9-point scale lies between, $1=$ dislike extremely to $9=$ like extremely) as described by Amerine et al. (1965).

\section{Texture profile analysis}

Low-calorie Milk Cake was analyzed for different textural parameters like hardness, gumminess, and chewiness using a texture profile analyzer (Model TA-XT Plus, UK). In this experiment cylindrical probe $(\mathrm{p} / 75)$ was used, the size of the sample 
was $20 \mathrm{~mm}$ in height and $20 \mathrm{~mm}$ width. The product was subjected to compressive force by probe up to a distance of $20 \mathrm{~mm}$ twice. The conditions of texture analyzer set for measuring textural properties are as follows: pre-test speed $2 \mathrm{~mm} / \mathrm{sec}$ and test and post-test speed was $0.5 \mathrm{~mm} / \mathrm{sec}$, trigger force $5.0 \mathrm{~g}$ and time 5.0 $\mathrm{sec}$ for each evaluation, about $25 \mathrm{~g}$ was used during texture analysis.

\section{Color analysis}

The color of Low-calorie Milk Cake was measured with a hunter color lab equipped with a measuring head (diameter $127 \mathrm{~mm}$ ). Low-calorie milk cake was crushed, filled three fourth into the measuring head and color was evaluated. The Hunter L, a, b color scale indicates color as $\mathrm{L}, \mathrm{a}, \mathrm{b}$ where $\mathrm{L}^{*}$ scale indicates Light Vs dark where a low number (0-50) indicates dark and a high number (51-100) indicates light, a* scale indicates red Vs green where a positive number indicates red and negative number indicates green and $b^{*}$ scale depicts yellow Vs blue where a positive number indicates yellow and negative number indicates blue. The $\mathrm{L}^{*}$ value for each scale, therefore, indicates the level of light or dark, the* value redness or greenness, and $b^{*}$ value yellowness or blueness. All three values are required to completely describe an object's color.

\section{Physicochemical analysis of low-calorie milk cake}

Physicochemical parameters such as \% protein, fat, Moisture, and ash content were determined as per the method described by AOAC (1995). Reducing sugar content in Low-Calorie Milk Cake was determined as per the method recommended by Miller et al. (1959).

\section{Energy value}

Energy value was measured using bomb calorimeter. About $1 \mathrm{~g}$ of the sample was weighed in a crucible and placed inside a stainless-steel container (the "decomposition vessel") filled with 30 bar (435psi) of oxygen. Next, the sample was ignited through a cotton thread connected to an ignition wire inside the decomposition vessel and burned (combusted). During combustion, the core temperature in the crucible can rise up to $1000^{\circ} \mathrm{C}\left(1800^{\circ} \mathrm{F}\right)$, and the pressure rises for a short period of time to approximately 200 bar (2900psi), or sometimes even higher. All organic matter is burned under these conditions and oxidized. Inorganic matter (minerals) will be oxidized; often, even vitrification takes place. The heat created during the burning process can be determined in different ways. After the combustion process was completed the energy value was displayed on the screen in terms of $\mathrm{cal} / \mathrm{g}$.

\section{Statistical analysis}

The data obtained during the present investigation were suitably analyzed by employing statistical designs. Response surface methodology (RSM) was used to optimize the various parameters such as milk fat, artificial sweetener and gum acacia level for optimization of Low-calorie milk cake. The results of preliminary studies are expressed as a mean \pm standard error. Statistical significance was tested by employing one-way \& two-way analysis of variance (ANOVA) and comparison between means was made by least significant difference pairwise comparison. For computation of data, software application programmes like Minitab 18 were used.

\section{Results and discussion}

Response surface methodology (RSM) was used to optimize the various independent parameters such as milk fat, artificial sweetener and gum acacia level for optimization of Low-calorie milk cake based on various sensorial and textural attributes. Color analysis mainly a* (Redness) was also considered for optimization of product for the various independent parameters Table 2. The quadratic models for various sensorial and textural parameters were obtained through successive regression analysis. The partial regression coefficients for $\%$ yield in terms of linear order, second order, and interaction of all three ingredients were included in Table 3.

\section{Optimization of milk cake on the basis of Sensory Evaluation}

\section{Effect on Color and Appearance}

The average color and appearance score varied from 7.5 to 8.0. Figure 2 (a) clearly depicts that with an increase in gum acacia level there was an increase in the color and appearance and with an increase in the level of milk fat the color and appearance decreases. Once the gum acacia was incorporated in the sample, it became slight brown in color. In the present study effect of gum acacia and level of milk fat on color and appearance could be described by the quadratic equation:

Table 1 Three independent process variables used in response surface methodology

\begin{tabular}{llllllc}
\hline Factor & Name & Units & Type & Subtype & Minimum & Maximum \\
\hline A & Milk fat & $\%$ & Numeric & Continuous & 1.0 & 3.0 \\
B & Artificial sweetener & $\%$ & Numeric & Continuous & 0.3 & 0.5 \\
C & Gum acacia & $\%$ & Numeric & Continuous & 0.3 & 1.0 \\
\hline
\end{tabular}


Toned milk (36.67lt.)

(3\%fat, $8.5 \% \mathrm{SNF})$

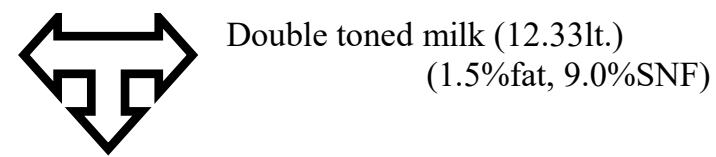

Standardized Milk (50lt.) by using Pearson square method (2.60\% fat and $8.5 \%$ SNF)

Boiled in karahi

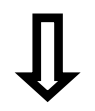

Added coagulating agent $(0.02 \%$ citric acid w/v, when the amount of milk was $50 \%$ reduced $)$

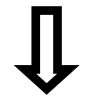

Added fat replacer $\mathbf{2 4 5}$ g (gum acacia @ 0.49\%)

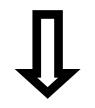

Desiccation is continued

Dough-like consistency is formed

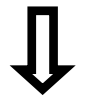

Added aspartame $\mathbf{1 1 . 5} \mathbf{g}$ (artificial sweetener @ 0.23\%w/v)

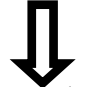

Transferred into the greasy tray

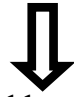

Put in an insulated box (for 5 to 6 hours)

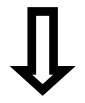

Low-calorie Milk Cake (11.5 kg)

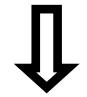

Stored at $5^{\circ} \mathrm{C}$

Fig. 1 Flow chart for the manufacturing of low-calorie milk cake

Color \& Appearance $=8.18-0.442 \mathrm{~A}-2.5 \mathrm{~B}+1.59 \mathrm{C}+0.102 \mathrm{~A} * \mathrm{~A}$

$+1.3 \mathrm{~B} * \mathrm{~B}-0.614 \mathrm{C} * \mathrm{C}+0.62 \mathrm{~A} * \mathrm{~B}$

Here A, B, and C are coded term for the variables milk fat, aspartame and gum acacia respectively. The coefficient of the estimate of color and appearance showed that the model was linear. The quadratic model for color and appearance was found to be significant $(p<0.0001)$. The coefficient of determination $\left(R^{2}\right)$ was 0.9362 . The "Pred R-Squared" of 0.8233 is in reasonable agreement with the "Adj R-Squared" of 0.9467. "Adeq Precision" was 21.435 and signal that ratio was greater than 4 was the desired value which indicates an adequate signal. Hence, the model could navigate the design space.

\section{Effect on flavor}




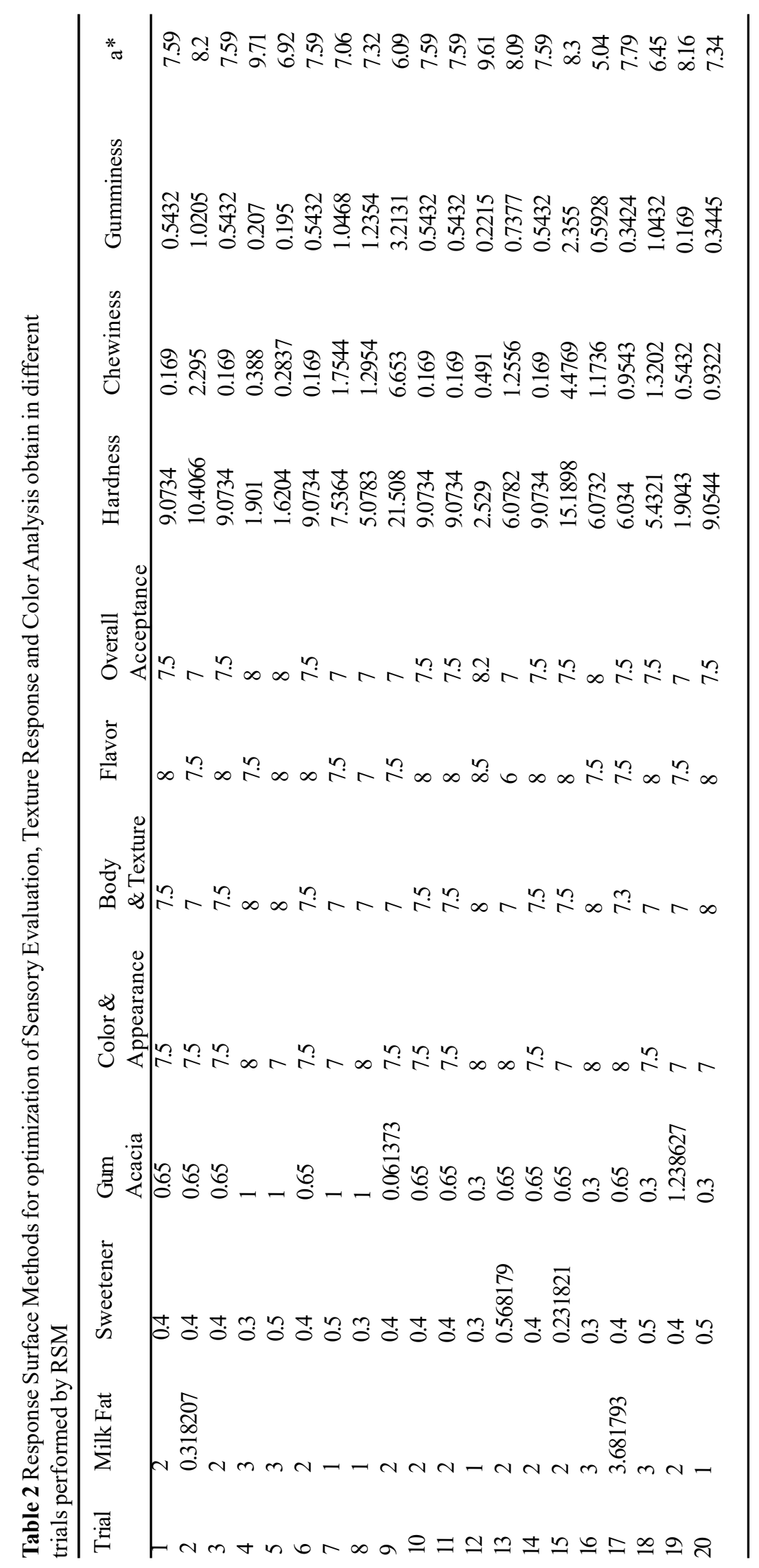




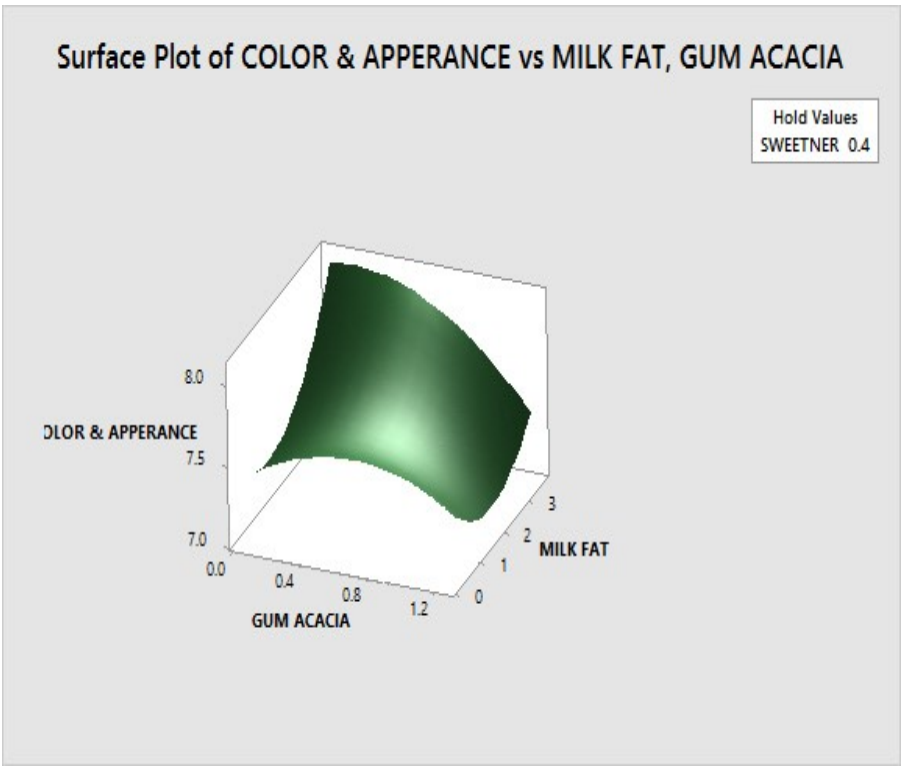

Surface Plot of BODY \& TEXTURE vs GUM ACACIA, SWEETNER

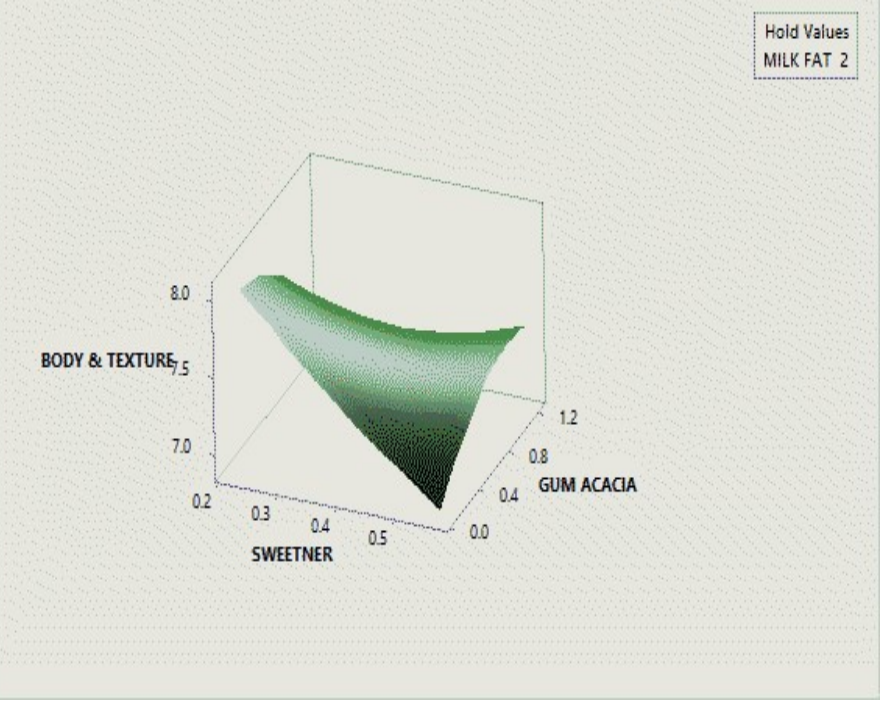

\section{Surface Plot of FLAVOR vs SWEETNER, MILK FAT}

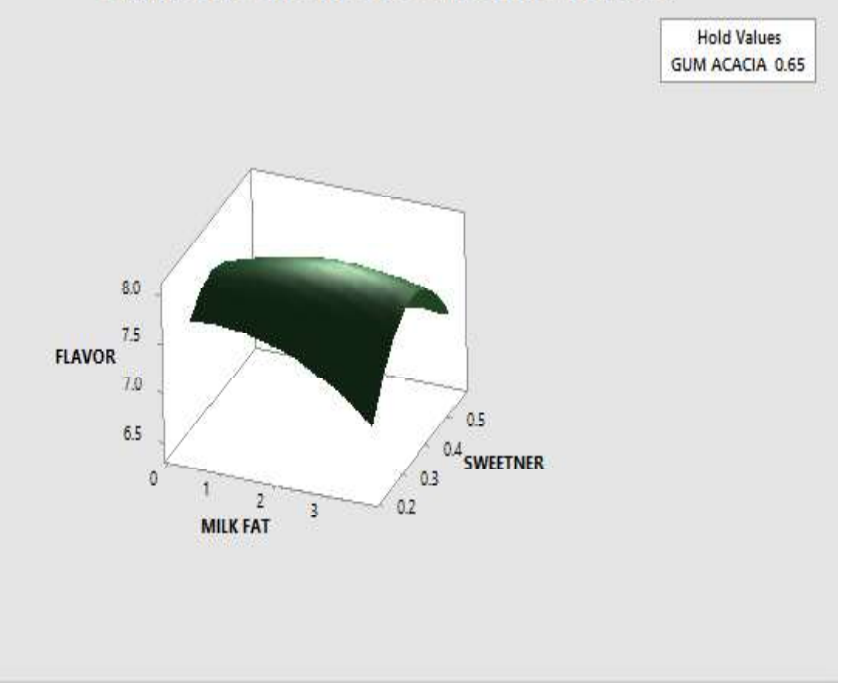

Surface Plot of OVER ALL ACCEPTANCE vs SWEETNER, GUM ACACIA

Hold Values

MILK FAT 2

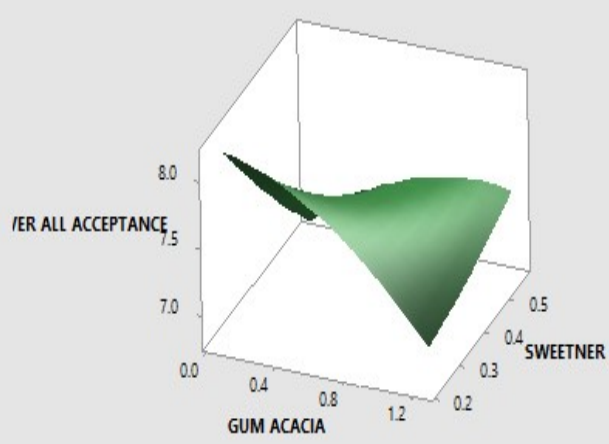

Figure 2 Response surface plot for Sensory parameters (a) Effect on Color and Appearance (b) Effect on Flavor (c) Effect on Body and Texture (d) Effect on Overall acceptability

The average flavor score for low-calorie milk cake varied from 7.5 to 8.0. Figure 2 (b) gives out the fact that with an increased level of milk fat and aspartame, the flavor score was initially increased and then decreased gradually. Baldwin and Korschgen (1997) reported that the various food and beverage flavor was enhanced or extended by incorporation of aspartame especially in the case of acidic fruit flavors. Such flavor extension is particularly evident with naturally dried flavors. Bahoshy et al. (1997) reported that the flavor enhancing property of aspartame was evident in chewing gum with increased flavor up to four times longer and such characteristics are promising for many food applications.
In the present study effect of Milk Fat and Aspartame on Flavor score could be described by the following equation:

Flavor $=7.09-0.643 \mathrm{~A}+14.0 \mathrm{~B}-2.42 \mathrm{C}-0.080 \mathrm{~A} * \mathrm{~A}-25.7 \mathrm{~B} * \mathrm{~B}-$ $0.66 \mathrm{C}^{*} \mathrm{C}+1.25 \mathrm{~A} * \mathrm{~B}+0.714 \mathrm{~A}^{*} \mathrm{C}+3.57 \mathrm{~B} * \mathrm{C}$

Here A, B, and C are encoded for the three variables milk fat, aspartame (artificial sweetener) and gum acacia. The quadratic model for flavor was significant at $(\mathrm{p}<0.0001)$. The coefficient of determination $\left(\mathrm{R}^{2}\right)$ was 0.8865 . The "Pred R-Squared" of 0.8233 is in reasonable agreement with the "Adj R-Squared" of 0.8267. "Adeq Precision" was 21.435 and signal that ratio was greater 


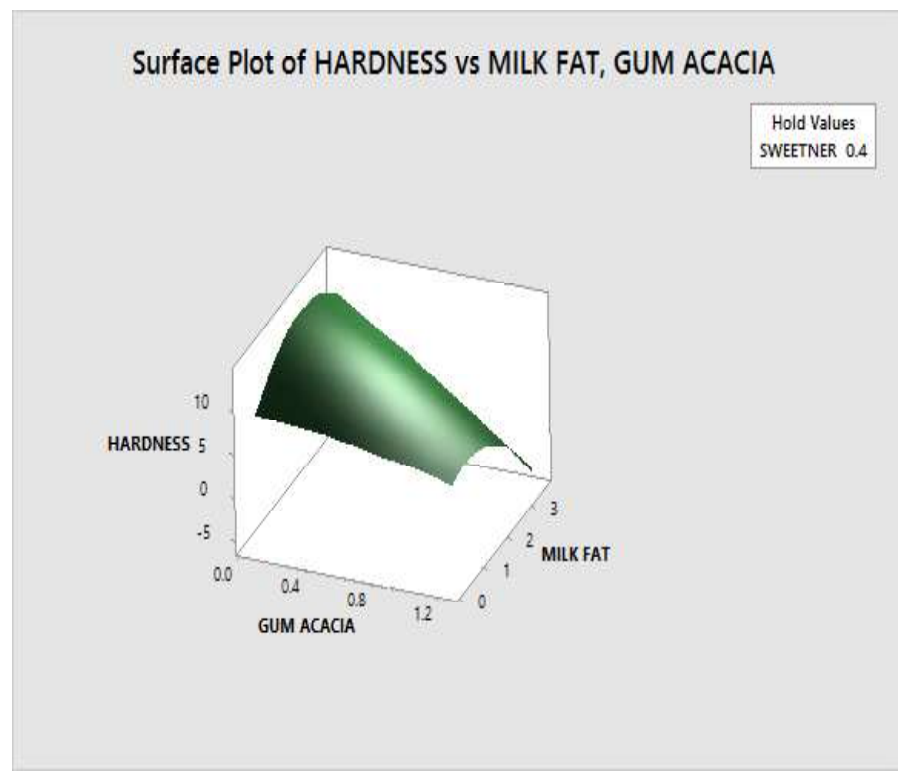

Surface Plot of CHEWINESS vS GUM ACACIA, MILK FAT

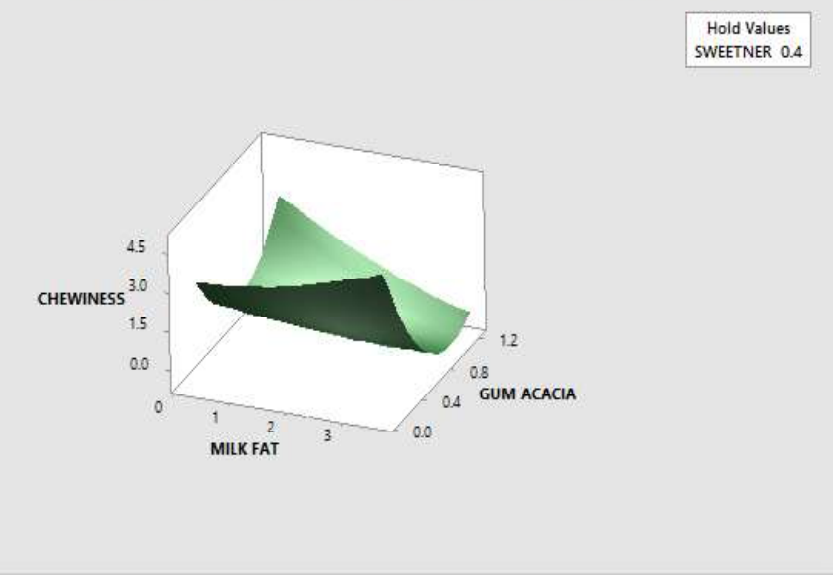

Surface Plot of GUMMINESS vs GUM ACACIA, SWEETNER

Hold Values MILK FAT 2

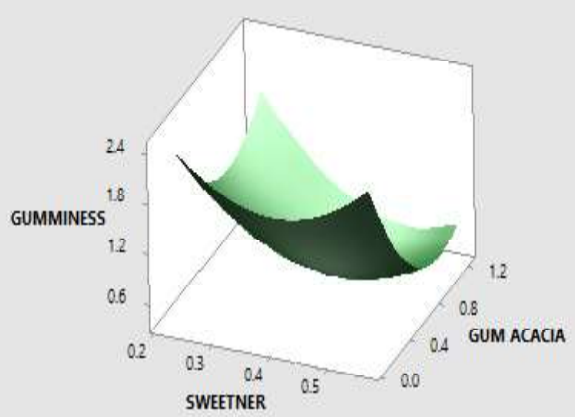

Figure 3 Response Surface plot for Textural parameters (a) Effect on Hardness (b) Effect on Gumminess (c) Effect on Chewiness

than 4 was the desired value which indicates an adequate signal. Hence, the model could navigate the design space.

\section{Effect on body and texture}

The average body and texture score for low-calorie milk cake was 7.3 to 8.0 (Table 2). Figure 2 (c) brings out the fact that with increase in level of gum acacia the body add texture score was also increased and increased in the level of aspartame had very slight effect on the body and texture and also the level of milk fat had some effect on body and texture, milk fat level increased they soften the body and texture. Tarrega and Costell (2006) studied that the observed change in the rheological behavior, induced by the inulin and gum acacia addition, may modify the sample texture perceived. The texture similar to fat can be obtained by increased in concentration. In the present study of gum acacia and sweetener to the body and texture could be described by the following equation:
Here A, B, and C are encoded for the three variables milk fat, aspartame (artificial sweetener) and gum acacia. The quadratic model for body and texture was found to be significant at $(p<0.0001)$. The coefficient of determination $\left(R^{2}\right)$ was 0.9065 . The "Pred R-Squared" of 0.8423 is in reasonable agreement with the “Adj R-Squared" of 0.8047. "Adeq Precision" was 20.012 and signal that ratio was greater than 4 was the desired value which indicates an adequate signal. Hence the model could navigate the design space.

\section{Effect on overall acceptance}




\section{Surface Plot of $a^{*}$ vs SWEETNER, GUM ACACIA}

Hold Values
MILK FAT 2

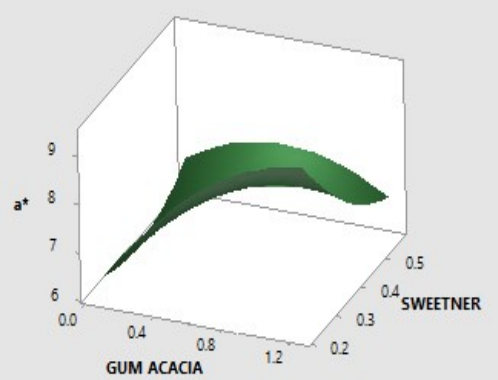

Fig. 4 Response Surface Plot shows the interaction between Gum Acacia, Artificial Sweetener and a* (Redness)

The maximum and minimum values obtained of overall acceptability were 8.2 and 7.5, respectively. The coefficient of determination $\left(\mathrm{R}^{2}\right)$ was 0.9645 . The "Pred R-Squared" of 0.9876 is in reasonable agreement with the "Adj R-Squared" of 0.9927. "Adeq Precision" was 21.435 and signal that ratio was greater than 4 was the desired value which indicates an adequate signal. Hence, the model could navigate the design space. Figure 2 (d) shows the effect of gum acacia, sweetener on overall acceptance of Low-Calorie Milk Cake. As the level of gum acacia increased

Table 3 Coefficient of estimation of coded factors for low-calorie milk cake

\begin{tabular}{lc}
\hline Factor & Coefficient of estimation \\
& Yield (\%) \\
\hline $\mathrm{A}$ & -0.095 \\
$\mathrm{~B}$ & 0.023 \\
$\mathrm{C}$ & 0.248 \\
$\mathrm{~A}^{2}$ & -0.313 \\
$\mathrm{~B}^{2}$ & -0.423 \\
$\mathrm{C}^{2}$ & -0.693 \\
$\mathrm{AB}$ & 0.124 \\
$\mathrm{AC}$ & -0.151 \\
$\mathrm{BC}$ & 0.041 \\
\hline
\end{tabular}

the overall acceptability was decreased whereas, it increases with increase in the level of aspartame (sweetener).

\section{Optimization of milk cake on the basis of texture profile analysis}

\section{Effect on hardness}

Figures 3 (a) shows that the hardness of product during texture profile analysis was significantly affected by gum acacia and milk fat. As the level of gum acacia increased the hardness of the product is also increased whereas, increased level of milk fat decreases the hardness of the product gradually. The average value for hardness was indicated in Table 2. The effect of aspartame was negligible on the hardness of the product. The effect of gum acacia and milk fat on the hardness of the product described by the following equation:

Hardness $=-14.0+11.56 \mathrm{~A}+74 \mathrm{~B}+5.5 \mathrm{C}-1.43 \mathrm{~A} * \mathrm{~A}-58 \mathrm{~B} * \mathrm{~B}-$ 1.6 C*C- $12.4 \mathrm{~A} * \mathrm{~B}-3.22 \mathrm{~A} * \mathrm{C}-13.2 \mathrm{~B}{ }^{*} \mathrm{C}$

Here A, B, and C are encoded by the three independent variables milk fat, aspartame and gum acacia. The quadratic model for Hardness was significant at $(\mathrm{p}<0.0001)$. The coefficient of determination $\left(\mathrm{R}^{2}\right)$ was 0.8762 . The "Pred R-Squared" of 0.8039 is in reasonable agreement with the "Adj R-Squared" of 0.8342 . Hence the model could navigate the design space.

\section{Effect on gumminess}

The gumminess of the Low-Calorie Milk Cake was significantly affected by gum acacia, milk fat and slightly affected by

Table $4 \mathrm{p}$ and $\mathrm{R}^{2}$ value of regression equation of suggested model for sensory, textural and Colour Characterstics

\begin{tabular}{llllllllc}
\hline & C\&A & B\&T & Flavour & OAA & Hardness & Chewiness & Gumminess & $\mathrm{a}^{*}$ \\
\hline $\mathrm{p}$ value & $\mathrm{p}<0.0001$ & $\mathrm{p}<0.0001$ & $\mathrm{p}<0.0001$ & $\mathrm{p}<0.0001$ & $\mathrm{p}<0.0001$ & $\mathrm{p}<0.0001$ & $\mathrm{p}<0.0001$ & $\mathrm{p}<0.0001$ \\
$\mathrm{R}^{2}$ & 0.9362 & 0.9065 & 0.8865 & 0.9645 & 0.8762 & 0.8683 & 0.7983 & 0.7643 \\
Pred R-Squared & 0.8233 & 0.8423 & 0.8233 & 0.9876 & 0.8039 & 0.7925 & 0.8033 & 0.7925 \\
Adj R-Squared & 0.9467 & 0.8047 & 0.8267 & 0.9927 & 0.8342 & 0.7835 & 0.6685 & 0.8423 \\
Adeq Precision & 21.435 & 20.012 & 21.43 & 21.435 & & 19.231 & 17.23 & 18.20 \\
Model & Linear & Linear & Linear & Linear & Linear & Linear & Linear & Linear \\
\hline
\end{tabular}


aspartame. Gum acacia had shown the highest ability to give gummy texture and also provide the binding properties so they help to bind the product. Figure 3(b) shows the interaction between the gumminess and the independent variable. The average value of gumminess was 0.169 to $3.25 \mathrm{~g}$. The level of milk fat increased the gumminess of the product is decreased gradually. There was no very slight effect of sweetener on the gumminess of the product. The present study of the effect of milk fat, aspartame, and gum acacia are described by the following equation:

Gumminess $=4.19+0.72 \mathrm{~A}-17.0 \mathrm{~B}-0.40 \mathrm{C}-$ $0.108 \mathrm{~A} * \mathrm{~A}+19.8 \mathrm{~B} * \mathrm{~B}+2.04 \mathrm{C} * \mathrm{C}+0.63 \mathrm{~A} * \mathrm{~B}-1.054 \mathrm{~A} * \mathrm{C}-$ $2.76 \mathrm{~B} * \mathrm{~B}$

Here A, B, and C are encoded for the three variables milk fat, aspartame, and gum acacia. The quadratic model for Gumminess was significant at $(p<0.0001)$. The coefficient of determination $\left(\mathrm{R}^{2}\right)$ was 0.7983 . The "Pred R-Squared" of 0.8033 is in reasonable agreement with the "Adj R-Squared" of 0.6685 . "Adeq Precision" was 17.23 and signal that ratio was greater than 3 was the desired value which indicates an adequate signal. Hence, the model could navigate the design space.

\section{Effect on chewiness}

The Figure 3(c) shows chewiness of the low-calorie milk cake was significantly affected by gum acacia the concentration of gum acacia increased the chewiness was decreased and the level of milk fat increased the chewiness was high at the low and high level of milk fat and low at the mid value. The minimum and maximum values for Chewiness were 0.169 to 3.23 . The present effect of gum acacia and milk fat was described by the following equation:

Chewiness $=12.93+0.51 \mathrm{~A}-44.9 \mathrm{~B}-8.02 \mathrm{C}+0.115 \mathrm{~A} * \mathrm{~A}+55.4 \mathrm{~B} * \mathrm{~B}$

$+6.63 \mathrm{C}^{*} \mathrm{C}-1.07 \mathrm{~A} * \mathrm{~B}-1.23 \mathrm{~A} * \mathrm{C}-0.8 \mathrm{~B} * \mathrm{C}$

Here A, B, and C are encoded for the three variables milk fat, aspartame, and gum acacia. The quadratic model for Chewiness was significant at $(\mathrm{p}<0.0001)$. The coefficient of determination $\left(\mathrm{R}^{2}\right)$ was 0.8683 . The "Pred R-Squared" of 0.7925 is in reasonable agreement with the "Adj R-Squared" of 0.7835. "Adeq Precision" was 19.231 and signal that ratio was greater than 4 was the desired value which indicates an adequate signal. Hence the model could navigate the design space.

\section{Optimization of milk cake on the basis of color evaluation}

\section{Effect on $a^{*}($ Redness)}

The effect of ingredients on the color of low-calorie milk cake is shown in figure $4 . a^{*}$ is the scale of color analysis that lies between -120 to 120 (green and red) where a positive number

indicates red and negative number indicates green. The maximum and minimum value of $a^{*}$ was ranged between 9.61 and 5.04. The value was fitted into the following quadratic equation:

Table 5 Analysis of optimized low-calorie milk cake

\begin{tabular}{llc}
\hline Attributes & & Value \\
\hline Physico-chemical & \% Protein & 17.31 \\
& \% Fat & 5.30 \\
& \% Carbohydrate & 57.79 \\
& \% Added sugar & 0.0 \\
& \% Moisture & 17.23 \\
\% Ash & 2.37 \\
Textural & Hardness & $9.032 \pm 0.023$ \\
& Gumminess & $0.890 \pm 0.05$ \\
Sensorial & Chewiness & $1.210 \pm 0.03$ \\
& Color and appearance & $8.32 \pm 0.003$ \\
& Body and texture & $8.23 \pm 0.015$ \\
\end{tabular}

Table 6 ANOVA on the predicted value of for the different sensory attributes of low calorie milk cake

\begin{tabular}{llll}
\hline Attributes & $\begin{array}{l}\text { Expected optimized } \\
\text { attributes }\end{array}$ & $\begin{array}{l}\text { Observed optimized } \\
\text { attributes }\end{array}$ & $p$-Value \\
\hline Color and appearance & 8.20 & $8.32 \pm 0.003$ & 0.931 \\
Body and texture & 7.55 & $8.23 \pm 0.015$ & 0.767 \\
Flavor & 7.94 & $7.32 \pm 0.005$ & 0.598 \\
Overall acceptability & 8.40 & $8.62 \pm 0.004$ & 0.890 \\
\hline
\end{tabular}


$\mathbf{a} *($ Redness $)=12.98-2.93 \mathrm{~A}-12.1 \mathrm{~B}+1.42 \mathrm{C}$ $+0.069 \mathrm{~A}^{*} \mathrm{~A}+14.0 \mathrm{~B} * \mathrm{~B}-1.95 \mathrm{C} * \mathrm{C}+1.44 \mathrm{~A} * \mathrm{~B}+2.754 \mathrm{~A} * \mathrm{C}-$ $7.82 \mathrm{~B} * \mathrm{C}$

Here A, B, and C are encoded for the three variables milk fat, aspartame, and gum acacia. The quadratic model for a* (Redness) was found to be significant at $(\mathrm{p}<0.0001)$. The coefficient of determination $\left(\mathrm{R}^{2}\right)$ was 0.7643 . The "Pred R-Squared" of 0.7925 is in reasonable agreement with the "Adj R-Squared" of 0.8423 . "Adeq Precision" -was 18.20 and signal that ratio was greater than 4 was the desired value which indicates an adequate signal. Hence, the model could navigate the design space (Table 2).

\section{Analysis of the optimized low-calorie milk cake}

Low-calorie milk cake was prepared as per the optimized formulation suggested by RSM software and was analyzed for various physicochemical, sensory and textural attributes as given in Table 5 and the predicted and observed value for different sensorial parameters are given in Table 6. Table 4 shows the $p$ value and other constraints of the applied model. The three independent variables were optimized at 2.61\%,0.23\% and $0.49 \%$ level for Milk fat, artificial sweeteners, and acacia gum, respectively and exhibit 0.86 desirabilities. Proximate composition of optimized low-calorie milk cake was found to be $17.31 \%$ protein, $5.30 \%$ fat, $17.23 \%$ moisture, $2.37 \%$ ash content and $0.0 \%$ added sugar. According to a market survey, the market sample of milk cake contained about $16.23 \%$ fat, $30.13 \%$ reducing sugar, 52$55 \%$ total carbohydrate $11.08 \%$ protein, $16.03 \%$ moisture and $2.67 \%$ ash content. So, in this study, the fat and sugar content was reduced about one-third of the amount present into the market milk cake.

\section{Energy value of low-calorie milk cake}

The energy value of Low-calorie milk cake was measured using bomb calorimeter as calorie per gram. The energy value of the control sample (market sample) was $6334.5 \mathrm{cal} / \mathrm{g}$ and the energy value of Low-calorie milk cake was $3782 \mathrm{cal} / \mathrm{g}$. So, the energy value of Low-calorie milk cake was nearly half of the control sample.

\section{Conclusions}

The optimization process for the development of low-calorie milk cake was found to be successful in reducing the calorific value of the milk cake using Responses Surface Methodology (RSM). The developed low-calorie milk cake is preferably formulated keeping in mind the low-calorie requirement of people with different dietary requirements as in this case it could be for suitable for consumption by diabetic people. Apart from sweetness provided by aspartame, the acacia gum provides excellent texture even at a low-fat percentage.

\section{References}

Amerine MA, Pangborn R, Roessler EB (1965) Principles of Sensory Evaluation of Food. New York: Academic Press

AOAC (1995) Official method of analysis of AOAC international vol.II $6^{\text {th }}$ edition, Verginia, USA

Bahoshy BJ, Klose RE, Nordstrom HA (1976) Chewing gums are a longer lasting sweetener and flavor. General Foods Crops US 3 Patent 943258

Baldwin RE, Korchgen BM (1979) Intensification of fruit flavors by aspartame. Journal of Food Science 44:938- 939

Bhutkar SS, Nimbalkar SS, Kumbhar TV (2015) Studies on effect of different levels of ash gourd pulp for manufacturing of kalakand. Journal of Agriculture and Veterinary Science 8(3):4-6

Dilek K, Zeynep H, Alev B, Sinan K (2007) Bubble and pore formation of the high-ratio cake formulation with polydextrose as a sugar and fat replacer. Journal of Food engineering 78:953-964

Karwasra RK, Srivastava DN, Hooda S (2001) Standardization of the Process for the Manufacture of Milk cake. Indian Journal of Dairy Science 54: 280-282

Magnuson BA, Burdock GA, Doull J, Kroes RM, Marsh GM, Pariza MW et al. (2007) Aspartame: a safety evaluation based on current use levels, regulations, and toxicological and epidemiological studies. Critical Reviews in Toxicology 37:629-727

Mathur BN (1991) Indigenous milk products of India: the related research and technological requirements. Indian Dairyman 43: 61-74

Miller GL (1959) Use of dinitrosalicylic acid reagent for determination of reducing sugar. Analytical Chemistry 31:426-429

NDDB (2017) National Dairy Development Board, Gujrat, India. http:// www.nddb.org/English/Statistics/pages/milkproduction.aspx.

Tarrega A, Costell E (2006) Effect of inulin addition on rheological and sensory properties of fat-free starch-based dairy desserts. International Dairy Journal 16:1104-1112 